\title{
Physiological response of Corynebacterium glutamicum to oxidative stress induced by deletion of the transcriptional repressor McbR
}

\section{Correspondence \\ Christoph Wittmann \\ c.wittmann@tu-bs.de}

Received 13 June 2008

Revised 13 August 2008

Accepted 20 August 2008

\author{
Jens O. Krömer, ${ }^{1} \dagger$ Christoph J. Bolten, ${ }^{1} \ddagger$ Elmar Heinzle, ${ }^{1}$ \\ Hartwig Schröder ${ }^{2}$ and Christoph Wittmann ${ }^{1} \ddagger$ \\ ${ }^{1}$ Biochemical Engineering Institute, Saarland University, Saarbrücken, Germany \\ ${ }^{2}$ BASF SE, Ludwigshafen, Germany
}

In the present work the metabolic response of Corynebacterium glutamicum to deletion of the global transcriptional regulator McbR, which controls, e.g. the expression of enzymes of Lmethionine and L-cysteine biosynthesis and sulfur assimilation, was studied. Several oxidative stress proteins were significantly upregulated among about 40 proteins in response to deletion of McbR. Linked to this oxidative stress, the mutant exhibited a $50 \%$ reduced growth rate, a $30 \%$ reduced glucose uptake rate and a $30 \%$ reduced biomass yield. It also showed metabolic flux rerouting in response to the deletion. NADPH metabolism was strongly altered. In contrast to the wild-type, the deletion strain supplied significantly more NADPH than required for anabolism, indicating the activity of additional NADPH-consuming reactions. These involved enzymes of oxidative stress protection. Through redirection of metabolic carbon flux in the central catabolism, including a $40 \%$ increased tricarboxylic acid (TCA) cycle flux, the mutant revealed an enhanced NADPH supply to provide redox power for the antioxidant systems. This, however, was not sufficient to compensate for the oxidative stress, as indicated by the drastically disturbed redox equilibrium. The NADPH/NADP ${ }^{+}$ratio in C. glutamicum $\triangle m c b R$ was only 0.29 , and thus much lower than that of the wild-type (2.35). Similarly, the NADH/NAD ${ }^{+}$ratio was substantially reduced from 0.18 in the wild-type to 0.08 in the mutant. Deletion of McbR is regarded as a key step towards biotechnological L-methionine overproduction in C. glutamicum. C. glutamicum $\Delta m c b R$, however, did not overproduce L-methionine; this was very likely linked to the low availability of NADPH. Since oxidative stress is often observed in industrial production processes, engineering of NADPH metabolism could be a general strategy for improvement of production strains. Unlike the wild-type, C. glutamicum $\Delta m c b R$ contained large granules with high phosphorus content. The storage of these energy-rich polyphosphates is probably the result of a large excess of formation of ATP, as revealed by estimation of the underlying fluxes linked to energy metabolism.

\section{INTRODUCTION}

Most amino acids are today produced by fermentation. In contrast, methionine, an important additive in animal nutrition, is still synthesized by a chemical process that yields the racemic DL-mixture. Due to the hazardous chemicals required for chemical synthesis and indications that the L-isomer of methionine has a better bioavailability for breeding poultry and other animals (Baker \& Boebel,

tPresent address: Australian Institute for Bioengineering and Nanotechnology, University of Queensland, Brisbane, Australia.

‡Present address: Biochemical Engineering Institute, Technische Universität Braunschweig, Gaussstrasse 17, 38106 Braunschweig, Germany.

Abbreviations: CDM, cell dry mass; EDX, energy dispersive X-ray; PPP, pentose phosphate pathway; TCA cycle, tricarboxylic acid cycle.
1980; D’Mello \& Lewis, 1978; Friedman, 1999), biotechnological production of L-methionine has gained increasing interest in recent years. One of the most promising candidates for such a process is Corynebacterium glutamicum, a Gram-positive soil bacterium, which is the dominant micro-organism applied in industrial production of amino acids, including L-glutamate and L-lysine (Eggeling \& Sahm, 1999). In this light, the biosynthetic pathway for L-methionine has been studied intensively in recent years, including the unravelling of the underlying regulatory mechanisms (Haitani et al., 2006; Hwang et al., 1999, 2002; Kim et al., 2001; Krömer et al., 2006a; Lee \& Hwang, 2003; Park et al., 1998; Rey et al., 2003, 2005; Rückert et al., 2003, 2005). In this respect, the discovery of the transcriptional regulator $\mathrm{McbR}$ was a remarkable finding (Rey et al., 2003, 2005). McbR represses the 
transcription of almost all genes of L-methionine biosynthesis (Rey et al., 2005) and restricts the levels of the corresponding proteins (Rey et al., 2003). Therefore, deletion of this repressor was regarded as a major step towards an L-methionine-producing strain. It was found that McbR also regulates L-cysteine biosynthesis and the sulfur assimilation pathway, and causes various secondary changes in the expression of genes without a McbR binding site, suggesting a global regulatory role in C. glutamicum (Rey et al., 2005). Metabolic studies show that a $m c b R$ deletion mutant of the wild-type C. glutamicum ATCC 13032 does not overproduce L-methionine, but accumulates tremendous amounts of homolanthionine inside the cell, a so far unknown metabolite in C. glutamicum (Krömer et al., 2006a). The detailed investigation of the physiological response of C. glutamicum to deletion of McbR appears quite important in order to understand the metabolic consequences of the absence of this transcriptional regulator. In this regard, we have investigated the metabolic effects of McbR deletion in C. glutamicum by combining growth physiology experiments with analysis of the proteome, fluxome, metabolome and morphology. Linked to previous transcription analysis (Rey et al., 2005), our work provides a global insight into the metabolic and regulatory effects of deleting this central transcriptional regulator in C. glutamicum.

\section{METHODS}

Strains and media. The wild-type C. glutamicum ATCC 13032 was obtained from the American Type Culture Collection. The deletion mutant C. glutamicum ATCC $13032 \Delta m c b R$ was derived from the wild-type as described previously (Krömer et al., 2006a). Cells were maintained at $30{ }^{\circ} \mathrm{C}$ on agar plates containing complex medium with $10 \mathrm{~g}$ glucose $1^{-1}, 2.5 \mathrm{~g} \mathrm{NaCl} 1^{-1}, 2 \mathrm{~g}$ urea $1^{-1}, 5 \mathrm{~g}$ yeast extract $\mathrm{l}^{-1}$, $5 \mathrm{~g}$ beef extract $1^{-1}, 5 \mathrm{~g}$ polypeptone $1^{-1}, 20 \mathrm{~g}$ casamino acids $1^{-1}$ and $20 \mathrm{~g}$ agar $1^{-1}$. For the first pre-culture, the same medium without agar was used. For the second pre-culture and main cultivation, a minimal medium was applied that contained (per litre): 20 g glucose, $16 \mathrm{~g} \mathrm{~K}_{2} \mathrm{HPO}_{4}, 4 \mathrm{~g} \mathrm{KH}_{2} \mathrm{PO}_{4}, 10 \mathrm{~g}\left(\mathrm{NH}_{4}\right)_{2} \mathrm{SO}_{4}, 300 \mathrm{mg}$ 3,4-dihydroxybenzoic acid, $10 \mathrm{mg} \mathrm{CaCl}, 250 \mathrm{mg} \mathrm{MgSO}_{4} \cdot 7 \mathrm{H}_{2} \mathrm{O}, 10 \mathrm{mg}$ $\mathrm{FeSO}_{4} \cdot 7 \mathrm{H}_{2} \mathrm{O}, 10 \mathrm{mg} \mathrm{MnSO}_{4} \cdot \mathrm{H}_{2} \mathrm{O}, 2 \mathrm{mg} \mathrm{ZnSO}_{4} \cdot 7 \mathrm{H}_{2} \mathrm{O}, 200 \mu \mathrm{g}$ $\mathrm{CuSO}_{4} \cdot 5 \mathrm{H}_{2} \mathrm{O}, 20 \mu \mathrm{g} \mathrm{NiCl} \cdot 6 \mathrm{H}_{2} \mathrm{O}, 20 \mu \mathrm{g} \mathrm{Na} \mathrm{NoO}_{4} \cdot 2 \mathrm{H}_{2} \mathrm{O}, 100 \mu \mathrm{g}$ cyanocobalamin, $300 \mu \mathrm{g}$ thiamine, $4 \mu \mathrm{g}$ pyridoxal phosphate, and $100 \mu \mathrm{g}$ biotin. In ${ }^{13} \mathrm{C}$ tracer experiments, $99 \%\left[1-{ }^{13} \mathrm{C}\right]$ glucose was used as substrate in equimolar amounts.

Cultivation. Single colonies were used as inoculum for the first preculture, which was grown at $30{ }^{\circ} \mathrm{C}$ for about $8 \mathrm{~h}$ in $250 \mathrm{ml}$ baffled shake flasks with $25 \mathrm{ml}$ medium on a rotary shaker (230 r.p.m., $2.5 \mathrm{~cm}$ shaking diameter, Multitron, Infors). Subsequently, cells were harvested by centrifugation ( $2 \mathrm{~min}, 10000 \mathrm{~g}, 4{ }^{\circ} \mathrm{C}$ ), washed twice with sterile $0.9 \% \mathrm{NaCl}$, and used for inoculation of the second preculture, which was cultivated for about $12 \mathrm{~h}$ under the same conditions. The cells were harvested during the exponential growth phase as described above and used as inoculum for the main culture. The main cultivation was performed in a $500 \mathrm{ml}$ bioreactor (Meredos) containing $100 \mathrm{ml}$ medium at $30 \pm 0.1{ }^{\circ} \mathrm{C}$ and 1000 r.p.m. The $\mathrm{pH}$ was maintained at $7.00 \pm 0.05$ by addition of $2 \mathrm{M} \mathrm{NaOH}$. The dissolved oxygen during the fermentation was always above $30 \%$ air saturation. The aeration rate of $100 \mathrm{ml} \mathrm{min}^{-1}$ was controlled by a mass flow controller (Brooks Instruments). The composition of aeration and exhaust gases was measured online with a quadrupole mass spectrometer (Omnistar, Pfeiffer). The aeration gas contained carbon dioxide (in the range of 400-800 p.p.m.), which was considered in the flux calculations as described previously (Krömer et al., 2004). All process variables (temperature, $\mathrm{pH}$, agitation, gas flow, gas composition and dissolved oxygen) were collected by a process control system (Lucullus PIMS 2.1, Biospectra). Both strains were cultivated in three replicates each. One of the replicates contained ${ }^{13} \mathrm{C}$-labelled glucose for flux analysis. For metabolic profiling, samples for metabolome, proteome and morphological analysis were taken at different time points during the exponential growth phase from two of the parallel cultures.

Chemicals. Casamino acids, beef extract, polypeptone and yeast extract were purchased from Difco. All other chemicals were of analytical grade and obtained from Grüssing, Acros Organics, Merck, Aldrich, or Fluka. The $99 \%\left[1-{ }^{13} \mathrm{C}\right]$ glucose was purchased from Cambridge Isotopes. The $\mathrm{H}_{2}{ }^{18} \mathrm{O}(95 \%)$ required for quantification of $S$-adenosyl methionine (Krömer et al., 2006b) was obtained from Campro Scientific.

Sampling and metabolite extraction. For quantification of extracellular metabolites, culture supernatant was obtained by filtration (PVDF syringe filter, $0.45 \mu \mathrm{m}$ pore-size, Roth). For quantification of intracellular metabolites, different protocols were applied for sampling and cell extraction, depending on the analyte of interest. In the case of intracellular amino acids and intermediates of the L-methionine pathway, the protocol comprised cell separation by fast filtration and subsequent extraction in boiling water of the cells retained on the filter (Wittmann et al., 2004c). For analysis of intracellular organic acids, $10 \mathrm{ml}$ culture samples were transferred into pre-cooled glass vials incubated in liquid nitrogen. In parallel, supernatant samples were taken via separation of the cells by filtration ( $0.2 \mu \mathrm{m}$ pore-size, Sartorius) to account for metabolites occurring in the medium (Bolten et al., 2007). Metabolite extraction followed a previous protocol (Becker et al., 2007). Due to the inherently low levels and time constants, the analysis of the intracellular nucleotides $\mathrm{NAD}^{+}, \mathrm{NADH}, \mathrm{NADP}^{+}$and NADPH also required an efficient quenching step. The above protocol with quenching of the whole culture in liquid nitrogen, however, was not compatible with the subsequent enzymic cycling assay due to the high salt content of the resulting extract. Accordingly, quenching in cold methanol was applied (Moritz et al., 2000). This does lead to leakage of intracellular metabolites during the quenching step, so that no absolute levels for the nucleotides could be obtained. The assumption that the reduced and oxidized forms of each nucleotide are subjected to the same extent of leakage, however, allowed the determination of relative intracellular levels, i.e. the NADH: $\mathrm{NAD}^{+}$and NADPH:NADP ${ }^{+}$ ratios. This procedure is justified by the fact that metabolic leakage is an unspecific phenomenon with a similar extent of leakage for different metabolites (Bolten et al., 2007), especially with regard to the high structural similarity of the compounds considered here. The nucleotides were extracted from quenched cells as described elsewhere (Moritz et al., 2000).

Analysis of substrates and products. The cell concentration throughout the cultivation was analysed via the $\mathrm{OD}_{660}$. The correlation between cell dry mass $(\mathrm{CDM})$ and $\mathrm{OD}_{660}$ was determined for exponentially growing cells as described previously (Krömer et al., 2004). The correlation was $\mathrm{CDM}\left(\mathrm{g} \mathrm{l}^{-1}\right)=0.39 \times \mathrm{OD}_{660}$ for the wildtype and $\mathrm{CDM}\left(\mathrm{g} \mathrm{l}^{-1}\right)=0.34 \times \mathrm{OD}_{660}$ for C. glutamicum $\Delta m c b R$. Amino acids and intermediates of the L-methionine pathway were quantified by HPLC with fluorescence detection (Agilent 1100), applying pre-column derivatization using ortho-phthalaldehyde (OPA) and $\alpha$-aminobutyrate as internal standard as described previously (Krömer et al., 2005), except that a Gemini column $(5 \mu \mathrm{m}, 150 \times 4.6 \mathrm{~mm}$, Phenomenex $)$ was used and 3-mercaptopro- 
pionic acid was applied as thiol reagent. The latter column offered a higher resolution of the analytes, which was advantageous for the complex cell extract samples, especially for the analysis of $O$-acetyl-Lhomoserine, cystathionine and L-methionine. The limit of detection for amino acids and methionine intermediates was $0.1 \mu \mathrm{mol}(\mathrm{g}$ $\mathrm{CDM})^{-1}$ for cell extracts and $10 \mu \mathrm{mol} 1^{-1}$ for culture supernatants. For homolanthionine quantification, an HPLC standard was synthesized to overcome the limitations of previous work, which was based on external calibration with homocystathionine, since homolanthionine itself was commercially unavailable. The synthesis of homolanthionine was carried out in vitro from O-acetyl-Lhomoserine and L-homocysteine, using purified MetB enzyme from C. glutamicum (Krömer et al., 2006a). After threefold recrystallization, homolanthionine was obtained with a purity of $97.5 \%$, as checked by HPLC analysis, and was used for HPLC calibration. Organic acids and sugars were quantified by HPLC (Biotek), employing an Aminex HPX $87 \mathrm{H} 300 \times 7.8 \mathrm{~mm}$ column (Bio-Rad) as stationary phase and $5 \mathrm{mM}$ $\mathrm{H}_{2} \mathrm{SO}_{4}$ as mobile phase at $1 \mathrm{ml} \mathrm{min}{ }^{-1}$ and $40{ }^{\circ} \mathrm{C}$. Detection was performed using UV $(220 \mathrm{~nm})$ and refractive index (RI), respectively. For sugars, the limit of detection was $10 \mu \mathrm{mol} \mathrm{l}^{-1}$, whereas it was in the range of $1-10 \mu \mathrm{mol} 1^{-1}$ for the different organic acids. NADH, $\mathrm{NAD}^{+}, \mathrm{NADPH}$ and $\mathrm{NADP}^{+}$were quantified via enzymic cycling (Bernofsky \& Swan, 1973). S-Adenosyl methionine was quantified by GC-MS (Krömer et al., 2006b).

GC-MS labelling analysis. Mass isotopomer fractions of amino acids from the cell protein were determined by GC-MS. For this purpose, cells (about 1-2 mg CDM) were harvested from the culture and washed twice with deionized water. The pellet was then incubated with $500 \mu \mathrm{l} 6 \mathrm{M} \mathrm{HCl}$ for $24 \mathrm{~h}$ at $105{ }^{\circ} \mathrm{C}$, subsequently neutralized with $6 \mathrm{M} \mathrm{NaOH}$ and cleared from insoluble matter by filtration ( $5 \mathrm{~min}$, ultrafree-MC filter units, $0.22 \mu \mathrm{m}$ pore-size durapore membrane; Millipore). The remaining clear solution was lyophilized. GC-MS analysis of the amino acids was performed after derivatization into the $t$-butyl-dimethylsilyl derivative (Wittmann \& Heinzle, 2002). The GC-MS instrument comprised a HP 6890 GC (Hewlett Packard), an HP-5MS column $(30 \mathrm{~m} \times 0.25 \mathrm{~mm} \times 0.25 \mu \mathrm{m}$, Agilent $)$ and a quadrupole MS (MS 5973, Agilent). Further instrument settings were as previously described (Wittmann \& Heinzle, 2002). All samples were first measured in scan mode to check for potential isobaric interference between analytes and other sample components. The labelling patterns of the amino acids, i.e. the relative fractions of the different mass isotopomers, were then determined in four replicates via selective ion monitoring (SIM) of selected ion clusters. The labelling pattern of trehalose was determined from lyophilized cultivation supernatant from its trimethylsilyl derivative via the ion cluster at $m / z$ 361-367 (Kiefer et al., 2004). This ion cluster corresponds to a fragment ion that contains an entire monomer unit of trehalose and thus a carbon skeleton equal to that of glucose 6phosphate (Wittmann et al., 2004a). All trehalose measurements in SIM mode were performed in quadruplicate.

Metabolic network, biomass requirements and metabolic flux calculation. The metabolic network of C. glutamicum comprises all relevant pathways of the central metabolism for growth on glucose (Kiefer et al., 2004; Wittmann \& Heinzle, 2002). The precursor requirement for anabolism was calculated from the cellular composition, additionally including the extra demand for synthesis of intracellular homolanthionine (Wittmann \& de Graaf, 2005). For flux calculation, mass spectra of L-alanine, glycine, L-valine, L-serine, L-threonine, L-aspartate, L-glutamate, L-phenylalanine and L-lysine from the cell protein, and of trehalose from the supernatant, were corrected for the natural abundance of all stable isotopes and unlabelled biomass from the inoculum. It should be noted that mass spectra of other amino acids were not available due to too weak signals (L-tryptophan, L-cysteine, L-methionine, L-asparagine, Lglutamine, L-arginine), ambiguous fragment ions (L-leucine, L- isoleucine) or isobaric interference (L-proline). The corrected mass isotopomer distributions together with directly measured fluxes from the tracer study (glucose uptake, by-product formation, precursor demand for anabolism) and metabolite balances around intracellular pools were used to calculate the free fluxes in the network by using an isotopomer model implemented in Matlab 7.0 (Mathworks) as described previously (Wittmann \& Heinzle, 2001, 2002; Wittmann et al., 2004b). The set of fluxes that gave minimum deviation between experimental and simulated mass isotopomer fractions was taken as the best estimate for the intracellular flux distribution. The network was over-determined, so that a least-squares approach was possible. As error criterion, a weighted sum of least-squares was used (Wittmann \& Heinzle, 2002). Statistical analysis of the obtained fluxes was carried out by a Monte Carlo approach (Wittmann \& Heinzle, 2002). The statistical variation was done such that random errors were added to the datasets, assuming a normal distribution of measurement errors around previously obtained mean values. The normally distributed random errors were generated using the statistics toolbox of Matlab. The errors considered were the measurement errors of the MS analysis and of the stoichiometric data from the parallel cultivations. By this approach the statistical analysis yields information on accuracy and confidence directly related to the performed experiments. Subsequently, 100 independent parameter estimations were carried out for each strain, yielding 100 flux distributions with a corresponding mean value and an SD for each intracellular flux parameter, from which $90 \%$ confidence limits for the single parameters were calculated.

Estimation of redox metabolism. Based on the flux estimates, the relative flux of catabolic NADPH supply ( $\left.v_{\mathrm{NADPH} \text {,supply }}\right)$ and anabolic NADPH consumption ( $\left.v_{\mathrm{NADPH}, \mathrm{demand}}\right)$ was calculated as described previously (Becker et al., 2007). Thereby, glucose-6-phosphate dehydrogenase, 6-phosphogluconate dehydrogenase and isocitrate dehydrogenase were considered to catalyse NADPH-forming reactions (Wittmann \& de Graaf, 2005). The anabolic NADPH demand was obtained from previous estimates (Wittmann \& de Graaf, 2005), additionally considering the demand for biosynthesis of homolanthionine.

Estimation of energy metabolism. The catabolic supply of $\mathrm{NADH}$ and FADH ( $\left.v_{\mathrm{XADH} \text {,supply }}\right)$ was calculated as described previously (Becker et al., 2007). It included the contributions of glyceraldehyde-3-phosphate dehydrogenase, pyruvate dehydrogenase, $\alpha$-ketoglutarate dehydrogenase, fumarase and malate dehydrogenase, and also of anabolism $\left(Y_{\mathrm{NADH} / \mathrm{X}}\right)$ with a NADH production of $Y_{\mathrm{NADH} / \mathrm{X}}=3.2 \mathrm{mmol} \mathrm{g}^{-1}$ (Yang et al., 2006). Additionally the relative flux of catabolic ATP supply ( $\left.v_{\text {ATP,supply }}\right)$ and anabolic ATP consumption $\left(v_{\mathrm{ATP}, \text { consumption }}\right)$ was estimated. Taking all relevant reactions into account, $v_{\text {ATP,supply }}$ and $v_{\text {ATP,consumption }}$ can be calculated from the fluxes of the metabolic network of C. glutamicum.

$v_{\mathrm{ATP}, \text { supply }}=\left(v_{\mathrm{GADPH}}+v_{\mathrm{PDH}}-v_{\mathrm{PGI}}-v_{\mathrm{PFK}}+v_{\mathrm{XADH} \text {,supply }}\right) \times \mathrm{P} / \mathrm{O}$

$v_{\mathrm{ATP}, \text { consumption }}=Y_{\mathrm{X} / \mathrm{ATP}} / Y_{\mathrm{X} / \mathrm{S}}$

Here, $\mathrm{P} / \mathrm{O}$ denotes the $\mathrm{P}: \mathrm{O}$ ratio of the respiratory chain, $Y_{\mathrm{X} / \mathrm{ATP}}$ the stoichiometric ATP yield and $Y_{\mathrm{X} / \mathrm{S}}$ the experimentally determined biomass yield. For the energetic parameters, previous values considered as reasonable for C. glutamicum were taken into account. This included $Y_{\mathrm{X} / \mathrm{ATP}}=10.5 \mathrm{~g} \mathrm{~mol}^{-1}$ (de Hollander, 1994). For the $\mathrm{P}: \mathrm{O}$ ratio, earlier estimates range between 1.5 and 2.0 , so that here a mean value of 1.75 was assumed (de Hollander, 1994; Varela et al., 2003, 2004).

Proteome analysis. For proteome analysis, four samples were taken during exponential growth for each strain. The samples represented two time points from two parallel bioreactor cultivations. For this purpose, $20 \mathrm{ml}$ culture was transferred into a tube containing $10 \mathrm{ml}$ 
pre-chilled buffer $\left(0{ }^{\circ} \mathrm{C}, 20 \mathrm{mM}\right.$ Tris, $5 \mathrm{mM} \mathrm{MgCl}_{2}, 20 \mathrm{mM} \mathrm{NaN}_{3}$, $\mathrm{pH} 7.5)$ and centrifuged $\left(4{ }^{\circ} \mathrm{C}, 3750 \mathrm{~g}, 5 \mathrm{~min}\right.$, Function line, Thermo). After removal of the supernatant, cells were washed with $10 \mathrm{ml}$ fresh buffer and centrifuged again. After the second centrifugation step, the supernatant was removed. Cells were then shock-frozen in cold acetone $\left(-60{ }^{\circ} \mathrm{C}\right)$ and stored at $-70{ }^{\circ} \mathrm{C}$ until the preparation of protein extracts. For protein extraction, about $250 \mathrm{mg}$ cells (wet weight) was suspended in $750 \mu \mathrm{l}$ lysis buffer (20 mM Tris, 5 mM EDTA, pH 7.5) containing a protease inhibitor mix (Complete, Roche). Cell disruption was carried out at $4{ }^{\circ} \mathrm{C}$ in a mixer mill (Retsch, MM 2000) using $0.25-0.5 \mathrm{~mm}$ glass beads. Cell debris was removed by centrifugation $\left(50000 \mathrm{~g}, 1 \mathrm{~h}, 4{ }^{\circ} \mathrm{C}\right)$. Protein concentration was determined by the Popov method (Popov et al., 1975). For 2D polyacrylamide electrophoresis, crude protein extract with $30 \mu \mathrm{g}$ protein load was resuspended in $450 \mu \mathrm{l}$ rehydration buffer (8 $\mathrm{M}$ urea, $2 \mathrm{M}$ thiourea, $1 \%$ CHAPS, $20 \mathrm{mM}$ DTT, $1 \%$ Ampholines 3.5-10) and a few grains of bromophenol blue. For IEF, pre-cast $24 \mathrm{~cm}$ immobilized $\mathrm{pH}$ gradient (IPG) strips with a linear $\mathrm{pH}$ gradient of 4.5-5.5 (Amersham Biosciences) were used. This pI range covers by far the largest portion of the cytosolic proteins of $C$. glutamicum (Hermann et al., 2001) and gives the highest resolution. Proteins were focused in a Multiphor II IEF unit (Amersham Biosciences) using a gradient program up to $3500 \mathrm{~V}$ resulting in $65000 \mathrm{~V} \mathrm{~h}$ in total. Focused IPG strips were equilibrated twice for $15 \mathrm{~min}$ in a buffer containing $1.5 \mathrm{M}$ Tris/ $\mathrm{HCl}(\mathrm{pH} 8.8), 6 \mathrm{M}$ urea, $30 \%(\mathrm{v} / \mathrm{v})$ glycerol, $2 \%(\mathrm{w} / \mathrm{v})$ SDS, and $1 \%(\mathrm{w} / \mathrm{v})$ DTT. For the second equilibration step, DTT was replaced by $5 \%(\mathrm{w} / \mathrm{v})$ iodoacetamide with a few grains of bromophenol blue. The second dimension was run in SDS-12.5\% polyacrylamide gels in an Ettan Dalt apparatus (Amersham Biosciences) as recommended by the manufacturer. Gels were subsequently silver-stained in a custommade staining automat (Blum et al., 1987). Protein spots were excised from preparative Coomassie-stained gels $(300 \mu \mathrm{g}$ total protein load in each) and digested with modified trypsin (Roche) as described previously (Hermann et al., 2001). Mass spectrometric identification was performed on an LCQ advantage instrument (Thermo Electron) after nano-HPLC separation of the peptides (LC Packings Dionex RP18 column, length $15 \mathrm{~cm}$, internal diameter $75 \mu \mathrm{m})$, using the MASCOT software (Perkins et al., 1999). Detection of spots, matching of gels and quantification of proteins was done using Image-Master Platinum v5.0 (GE Healthcare). The relative amount of each of the affected proteins was quantified as the mean value from four gels for each strain.

Electron microscopy. Exponentially growing cells were harvested $\left(16000 \mathrm{~g}, 1 \mathrm{~min}, 30{ }^{\circ} \mathrm{C}\right)$, resuspended in $1 \mathrm{ml}$ fixation buffer $(1 \%$ paraformaldehyde, $1 \%$ glutaraldehyde, $0.1 \%$ saturated picric acid in $120 \mathrm{mM}$ phosphate buffer, pH 7.0, stained with phenol red) and stored at $4{ }^{\circ} \mathrm{C}$ until analysis. For transmission electron microscopy (TEM), cells were treated with $2 \% \mathrm{OsO}_{4}$ and embedded in epoxy resin. Subsequently obtained ultrathin sections were analysed with a Tecnai 12 microscope (FEI). For energy dispersive X-ray (EDX) analysis, unstained and unfixed cells were analysed using a Leo 912 Omega instrument (Zeiss).

\section{RESULTS}

\section{Cultivation characteristics}

The cultivation profiles of the C. glutamicum wild-type and the deletion mutant $C$. glutamicum $\Delta m c b R$ are shown in Fig. 1 . The deletion strain revealed a significantly reduced metabolic activity as reflected by the extended time period for glucose utilization and the reduced specific rates for

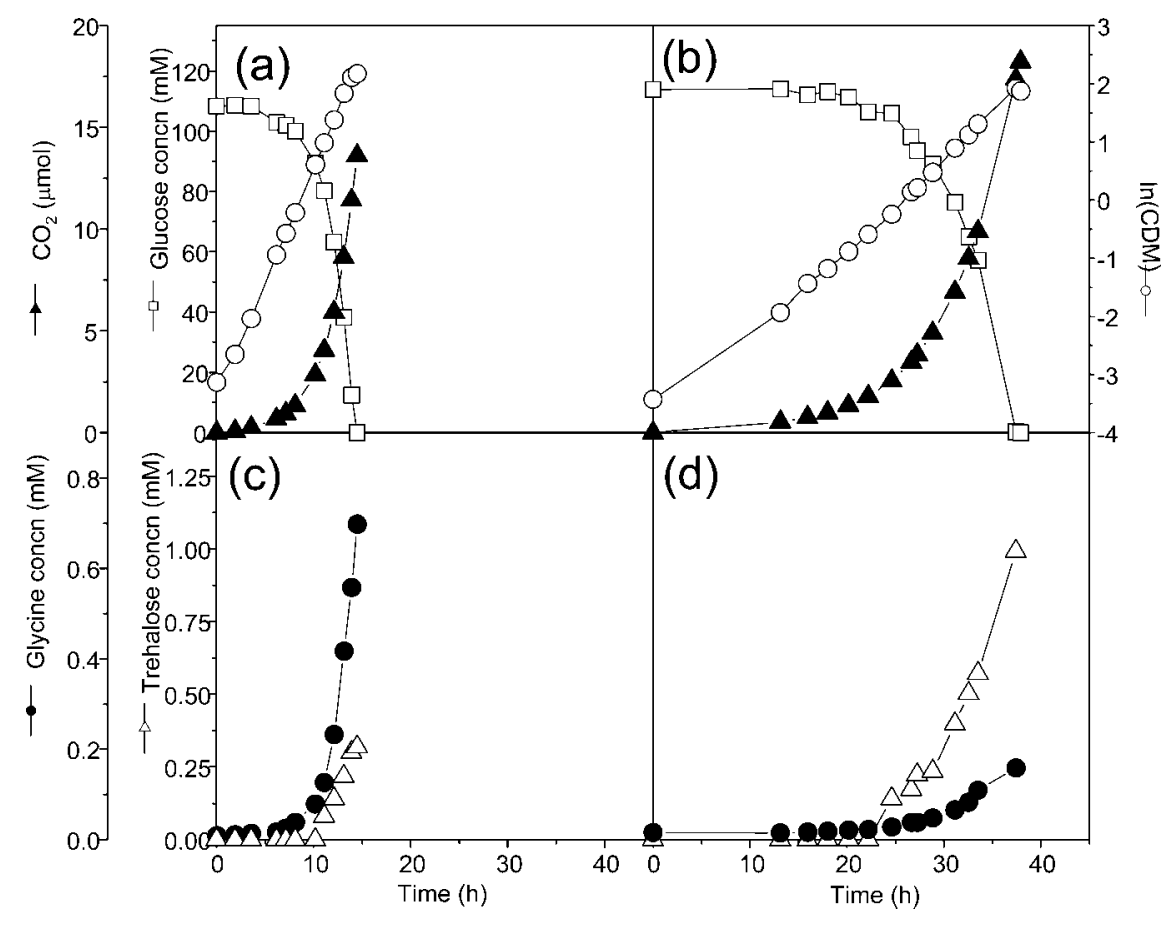

Fig. 1. Cultivation profile of C. glutamicum ATCC $13032(\mathrm{a}, \mathrm{c})$ and C. glutamicum ATCC $13032 \Delta m c b R(\mathrm{~b}, \mathrm{~d})$ on minimal glucose medium. Data comprise biomass concentration, glucose concentration and carbon dioxide produced (a,b), and concentrations of trehalose and glycine (c, d). 
growth and glucose uptake (Table 1). Further, it could not utilize glucose as efficiently for growth as the wild-type, as shown by the strongly reduced biomass yield. C. glutamicum $\Delta m c b R$ revealed an elevated production of $\mathrm{CO}_{2}$. Overall, the mutant produced around $56 \%$ more $\mathrm{CO}_{2}$ than the wild-type during the whole cultivation. In addition, deletion of McbR resulted in a change in the by-product spectrum. Whereas formation of trehalose was enhanced approximately threefold, secretion of glycine was reduced. Further by-products were not detected. Also, L-methionine was not detected in any of the cultivations. The mean respiratory quotient during the exponential growth phase was $1.00 \pm 0.03$ for the wild-type and $1.05 \pm 0.02$ for the mutant, indicating purely respiratory utilization of the carbon source. The linear correlation between biomass formed and glucose consumed from the three parallel cultures indicates metabolic steady-state during the cultivation of both strains and high reproducibility of the cultivation (Fig. 2).

\section{Morphology}

C. glutamicum $\triangle m c b R$ contained large spherical granules of increased electron density (Fig. 3a). These granules were not present in the wild-type (data not shown) and thus were specifically caused by the deletion of McbR. EDX analysis revealed that the granules had an elevated phosphorus content (Fig. 3b).

\section{Metabolic pathway fluxes}

The deletion of the regulatory protein McbR strongly affected the carbon fluxes in the central metabolism of $C$. glutamicum (Fig. 4). For both organisms, an excellent fit of

Table 1. Kinetic and stoichiometric characteristics of $C$. glutamicum ATCC 13032 and the deletion mutant C. glutamicum ATCC $13032 \Delta m c b R$ during exponential growth on glucose

The data given are biomass yield on glucose $\left(Y_{\mathrm{X} / \mathrm{Glc}}\right)$, specific growth rate $(\mu)$, specific glucose uptake rate $\left(q_{\mathrm{Glc}}\right)$ and yields for the byproducts glycine and trehalose. The yields were determined as the slope of the linear fit between biomass or by-product formation, respectively, and substrate consumption (compare with Fig. 2 for biomass). $\mu$ was estimated as the slope from the semi-logarithmic plot of cell concentration versus time (Fig. 1a, b). $q_{\mathrm{Glc}}$ was calculated from $\mu$ and the biomass yield on glucose. The data represent the mean values from three parallel cultivation experiments with corresponding SDS.

\begin{tabular}{|lcc|}
\hline Characteristic & Wild-type & $\boldsymbol{\Delta} \boldsymbol{m} \boldsymbol{c} \boldsymbol{b} \boldsymbol{R}$ \\
\hline$Y_{\mathrm{X} / \mathrm{Glc}}\left(\mathrm{g} \mathrm{g}^{-1}\right)$ & $0.49 \pm 0.03$ & $0.34 \pm 0.01$ \\
$\mu\left(\mathrm{h}^{-1}\right)$ & $0.42 \pm 0.02$ & $0.20 \pm 0.02$ \\
$q_{\mathrm{Glc}}\left(\mathrm{mmol} \mathrm{g}^{-1} \mathrm{~h}^{-1}\right)$ & $4.7 \pm 0.3$ & $3.3 \pm 0.3$ \\
$Y_{\text {Glycine/Glc }}\left(\mathrm{mmol} \mathrm{mol}^{-1}\right)$ & $6.2 \pm 0.5$ & $1.6 \pm 0.3$ \\
$Y_{\text {Trehalose/Glc }}\left(\mathrm{mmol} \mathrm{mol}^{-1}\right)$ & $3.3 \pm 0.4$ & $8.3 \pm 0.8$ \\
\hline
\end{tabular}

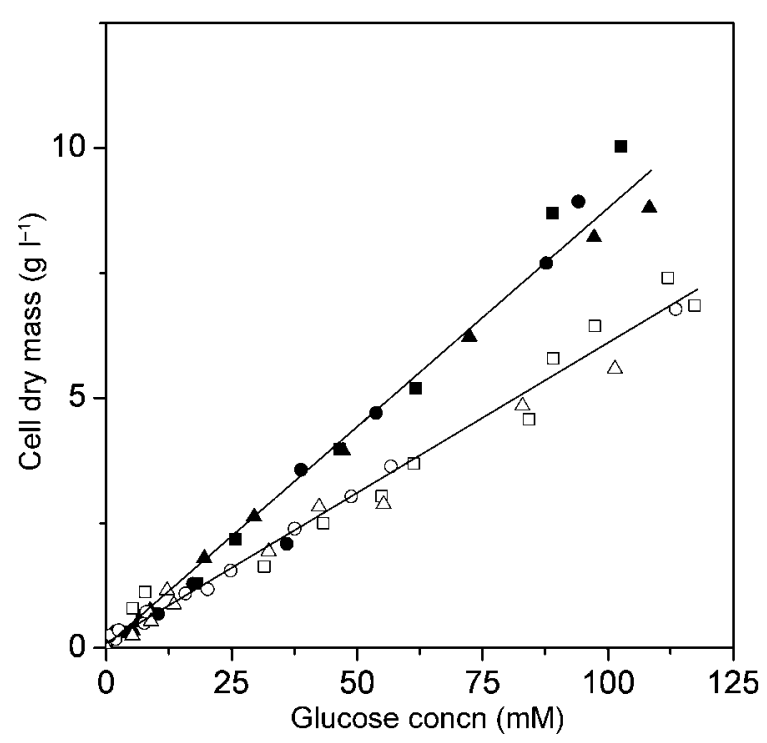

Fig. 2. Correlation between biomass produced and glucose consumed for glucose-grown C. glutamicum ATCC 13032 (filled symbols) and C. glutamicum ATCC $13032 \Delta m c b R$ (open symbols) from three independent cultivations, represented by squares, circles and triangles.

the labelling data was obtained, underlining the consistency of the determined fluxes (Table 2). With respect to the relative flux distribution, normalized to the glucose uptake rate, flux was redirected from the pentose phosphate pathway (PPP) into glycolysis in response to the deletion. The deletion of McbR further resulted in an increased relative flux through pyruvate dehydrogenase. Most striking was a strong increase of the relative flux through the TCA cycle in the deletion strain, which was almost $40 \%$ higher as compared with the wild-type. At the pyruvate node, the back flux, converting $\mathrm{C}_{4}$ metabolites of the TCA cycle into $\mathrm{C}_{3}$ metabolites of glycolysis, was increased by $40 \%$. The changes introduced through deletion of McbR further altered the redox metabolism. Through rearrangement of pathway fluxes, the deletion strain showed a strongly increased formation of NADPH. Whereas the wild-type had an almost equal NADPH supply $(151 \%)$ and demand $(147 \%)$, i.e. a closed NADPH balance, C. glutamicum $\Delta m c b R$ revealed an apparent excess of almost $70 \%$ (NADPH supply $179 \%$, NADPH demand $116 \%)$ for this cofactor. Due to the strongly reduced glucose uptake flux, which was about $30 \%$ lower in the deletion strain $\left(3.3 \mathrm{mmol} \mathrm{g}^{-1} \mathrm{~h}^{-1}\right)$ as compared with the wild-type $\left(4.7 \mathrm{mmol} \mathrm{g} \mathrm{g}^{-1} \mathrm{~h}^{-1}\right.$ ), most of the pathways and enzymes showed a reduced activity in terms of absolute carbon flux in response to McbR deletion. As an example, the absolute PPP flux in the mutant $\left(1.3 \mathrm{mmol} \mathrm{g}^{-1} \mathrm{~h}^{-1}\right)$ was only half that observed for the wild-type $(2.1 \mathrm{mmol}$ $\left.\mathrm{g}^{-1} \mathrm{~h}^{-1}\right)$. In contrast, absolute fluxes through the TCA cycle enzymes, e.g. citrate synthase $\left(2.9 \mathrm{mmol} \mathrm{g}^{-1} \mathrm{~h}^{-1}\right.$ for the wild-type; $3.2 \mathrm{mmol} \mathrm{g}^{-1} \mathrm{~h}^{-1}$ for the mutant) were 

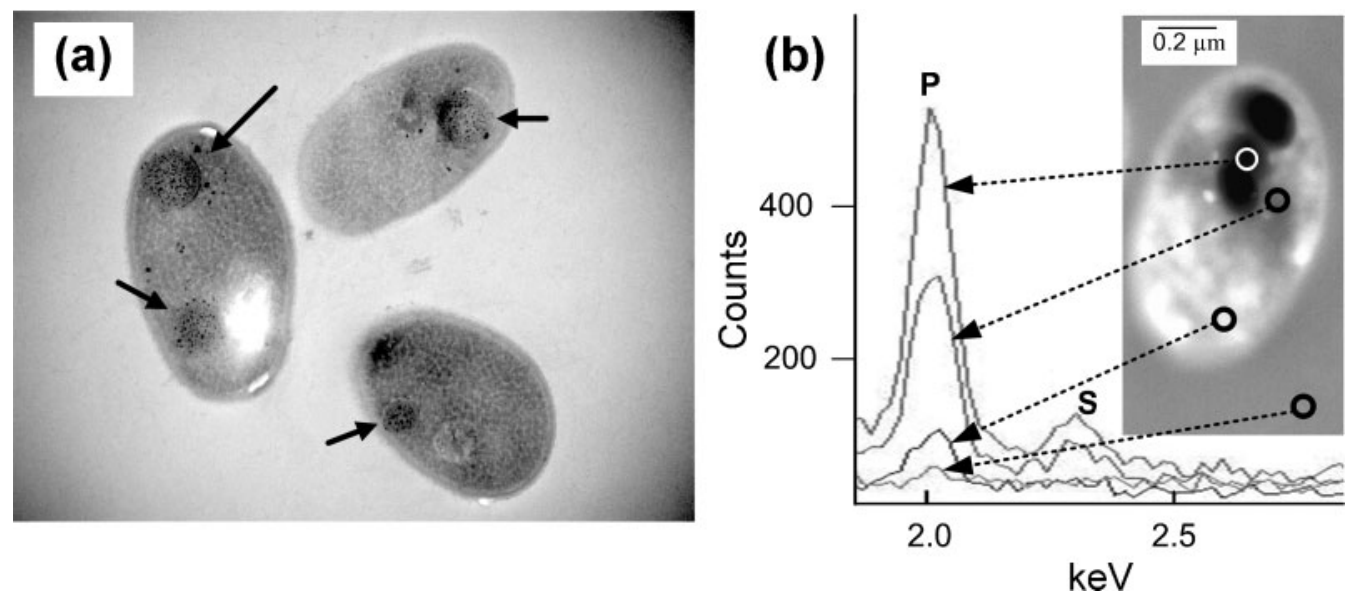

Fig. 3. Morphological analysis of C. glutamicum ATCC $13032 \Delta m c b R$. (a) Transmission electron micrograph of cells during exponential growth on minimal glucose medium with arrows indicating the granules. (b) Phosphorus (P) and sulfur (S) content of a granule, of the interface between granule and cytoplasm, of the cytoplasm and of the surrounding matrix, as obtained by electron dispersive $\mathrm{X}$-ray analysis from unstained and unfixed cells.

slightly higher in the deletion strain. Identical flux distributions were obtained in multiple parameter estimations with statistically varied starting values for the free fluxes, suggesting that the obtained result represents the global optimum of the solution. Statistical analysis revealed high precision for the obtained flux values, so that the differences observed between the wild-type and the McbR deletion strain are clearly strain-specific.

\section{Metabolite profile}

The intracellular levels of metabolites from L-methionine biosynthesis were strongly affected by the McbR deletion (Table 3). The first two pathway intermediates, L-homoserine and $O$-acetyl-L-homoserine, were reduced, whereas all others, including L-homocysteine, cystathionine, $S$ adenosyl methionine and L-methionine, showed increased intracellular levels. Most striking was the intracellular accumulation of homolanthionine in the deletion strain, which was not detected in the wild-type. McbR deletion further affected metabolites linked to $\mathrm{C}_{1}$ metabolism and sulfur assimilation. L-Serine and glycine were decreased, whereas the intracellular level of L-cysteine was eightfold higher. To overcome the potentially limited supply of serine as a $C_{1}$ donor, feeding of C. glutamicum $\Delta m c b R$ with $10 \mathrm{mM}$ L-serine in the culture broth led to an increased intracellular $\mathrm{L}$-methionine concentration $\left(0.7 \mu \mathrm{mol} \mathrm{g} \mathrm{g}^{-1}\right)$ compared with only $0.4 \mu \mathrm{mol} \mathrm{g}^{-1}$ without L-serine feeding and $<0.1 \mu \mathrm{mol} \mathrm{g}^{-1}$ in the wild-type strain.

The McbR deletion also had a strong influence on the cellular redox state. The $\mathrm{NADH}: \mathrm{NAD}^{+}$ratio of the mutant was only $0.08 \pm 0.04$ and thus significantly lower than that observed for the wild-type $(0.18 \pm 0.02)$. Similarly, the NADPH/ $\mathrm{NADP}^{+}$ratio was also drastically reduced, $0.29 \pm 0.18$ for the deletion strain as compared with $2.35 \pm 0.60$ for the wild- type. Other pools of the central carbon metabolism were influenced by the McbR knockout, underlining its global effect. For example, the levels of the branched-chain amino acids were significantly changed, whereby the increased level of L-isoleucine was obviously linked to increased availability of its precursor 2-oxobutanoate. Further effects of McbR deletion included elevated levels of the basic amino acids Larginine and L-lysine and of trehalose, acting as a compatible solute. The intracellular concentrations of the metabolites analysed generally showed small SDs, indicating high reproducibility and metabolic state during the cultivation.

\section{Proteome profile}

Proteome analysis of the wild-type and the deletion mutant $\Delta m c b R$ revealed about 40 proteins with significantly different spot size, all of which were upregulated in the mutant (Fig. $5 \mathrm{a}, \mathrm{b})$. The upregulated proteins comprised enzymes of Lmethionine and L-cysteine biosynthesis and sulfate assimilation (Table 4). C. glutamicum $\Delta m c b R$ further showed a strong induction of proteins linked to oxidative stress, such as catalase and FMN reductase. Also, enzymes of the central carbon catabolism, as well as those of vitamin, amino acid and iron metabolism, were affected, underlining the global cellular response to McbR deletion. In several cases the analysed spot comprised more than one protein, so that a clear identification of the protein influenced by the McbR deletion was not possible (Table 5). Most of the possible candidates from the MS analysis were enzymes of L-methionine and L-cysteine biosynthesis or related to oxidative stress.

\section{DISCUSSION}

In C. glutamicum, the transcriptional regulator McbR represses the expression of almost all genes of L-methionine 


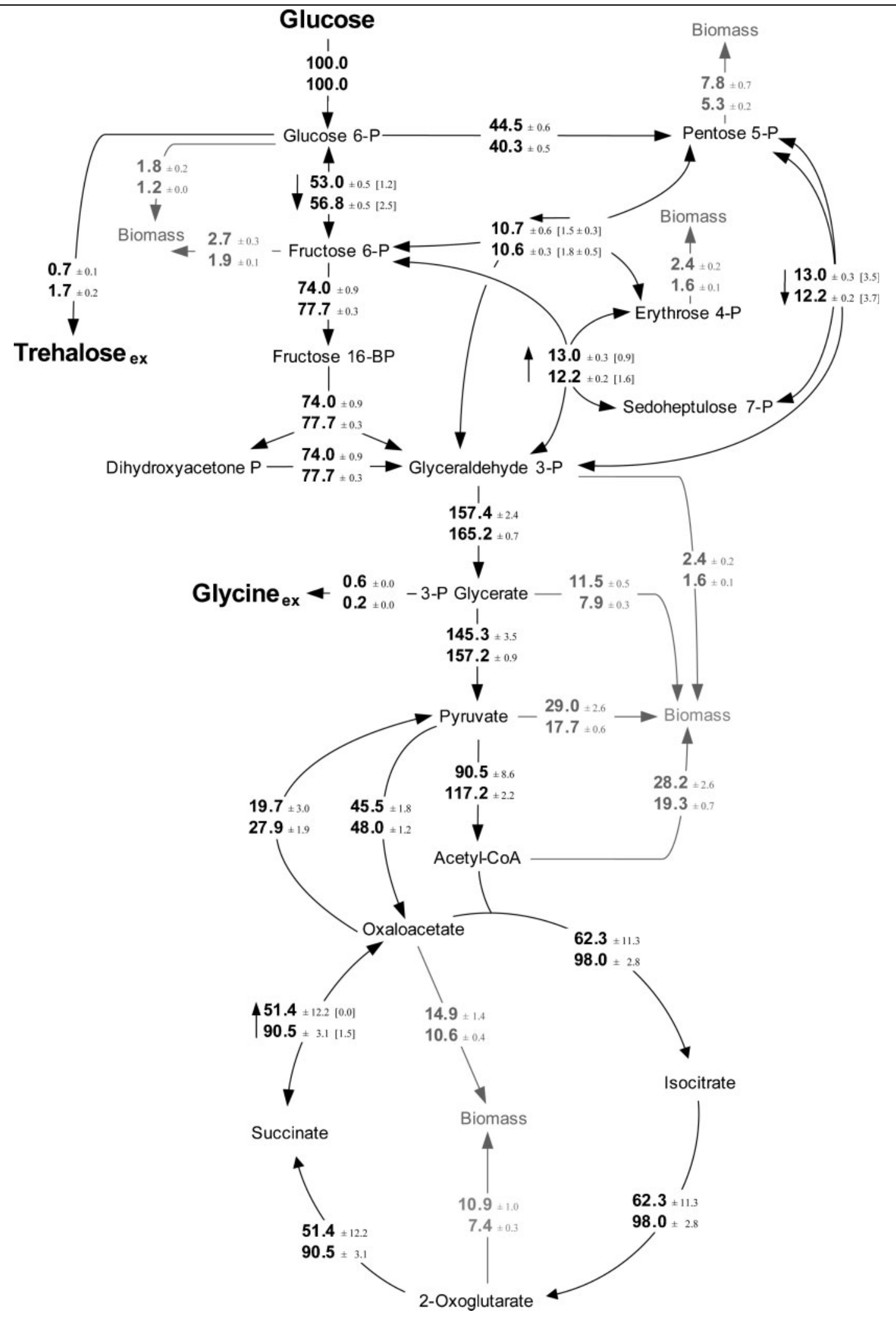

Fig. 4. In vivo carbon flux distribution in the central metabolism of C. glutamicum ATCC 13032 (upper numbers of each pair) and C. glutamicum ATCC $13032 \Delta m c b R$ (lower numbers of each pair) during growth on glucose. For reversible reactions, the direction of the net flux is indicated by an arrow beside the corresponding numbers. Numbers in brackets beside the reversible reactions indicate flux reversibility. All fluxes are expressed as the molar percentage of the mean specific glucose uptake rate (4.7 $\mathrm{mmol} \mathrm{g}^{-1} \mathrm{~h}^{-1}$ for the wild-type, $3.3 \mathrm{mmol} \mathrm{g}^{-1} \mathrm{~h}^{-1}$ for the deletion strain), which is defined as $100 \%$. Corresponding $90 \%$ confidence intervals are given. 
Table 2. Mass isotopomer fractions of amino acids from the cell protein and of secreted trehalose of C. glutamicum ATCC 13032 and C. glutamicum ATCC $13032 \Delta m c b R$ cultivated on $99 \%\left[1-{ }^{13} \mathrm{C}\right] g$ lucose

The data comprise experimental GC-MS data (exp) and values predicted by the solution of the mathematical model corresponding to the optimized set of fluxes (cal). The latter were corrected for the presence of natural isotopes to directly match the experimental data. M represents the amount of non-labelled mass isotopomer fraction, $\mathrm{M}+1$ the amount of singly labelled mass isotopomer fraction and corresponding terms refer to higher levels of labelling.

\begin{tabular}{|c|c|c|c|c|c|c|c|}
\hline \multirow[t]{2}{*}{ Metabolite } & & \multicolumn{3}{|c|}{ Wild-type } & \multicolumn{3}{|c|}{$\Delta m c b R$} \\
\hline & & $\mathbf{M}$ & $M+1$ & $M+2$ & $\mathbf{M}$ & $M+1$ & $M+2$ \\
\hline \multirow[t]{2}{*}{ Alanine $(m / z$ 260) } & $\mathrm{cal}$ & 0.502 & 0.359 & 0.108 & 0.482 & 0.370 & 0.114 \\
\hline & $\exp$ & 0.502 & 0.359 & 0.107 & 0.483 & 0.371 & 0.113 \\
\hline \multirow[t]{2}{*}{ Valine $(m / z 288)$} & $\mathrm{cal}$ & 0.336 & 0.400 & 0.190 & 0.311 & 0.403 & 0.204 \\
\hline & $\exp$ & 0.336 & 0.400 & 0.190 & 0.311 & 0.401 & 0.204 \\
\hline \multirow[t]{2}{*}{ Threonine $(\mathrm{m} / \mathrm{z} 404)$} & cal & 0.327 & 0.374 & 0.200 & 0.302 & 0.374 & 0.213 \\
\hline & $\exp$ & 0.327 & 0.375 & 0.200 & 0.302 & 0.375 & 0.214 \\
\hline \multirow[t]{2}{*}{ Aspartate $(m / z 418)$} & $\mathrm{cal}$ & 0.327 & 0.373 & 0.200 & 0.302 & 0.373 & 0.213 \\
\hline & $\exp$ & 0.328 & 0.373 & 0.200 & 0.303 & 0.376 & 0.213 \\
\hline \multirow[t]{2}{*}{ Glutamate $(m / z 432)$} & $\mathrm{cal}$ & 0.245 & 0.365 & 0.241 & 0.222 & 0.359 & 0.254 \\
\hline & $\exp$ & 0.244 & 0.362 & 0.242 & 0.222 & 0.355 & 0.254 \\
\hline \multirow[t]{2}{*}{ Lysine $(m / z 431)$} & cal & 0.223 & 0.357 & 0.253 & 0.199 & 0.346 & 0.265 \\
\hline & $\exp$ & 0.229 & 0.352 & 0.253 & 0.208 & 0.341 & 0.263 \\
\hline \multirow[t]{2}{*}{ Trehalose $(m / z 361)$} & cal & 0.060 & 0.613 & 0.204 & 0.074 & 0.589 & 0.210 \\
\hline & $\exp$ & 0.060 & 0.616 & 0.205 & 0.074 & 0.594 & 0.213 \\
\hline \multirow[t]{2}{*}{ Serine $(m / z 390)$} & $\mathrm{cal}$ & 0.443 & 0.362 & 0.144 & 0.430 & 0.370 & 0.149 \\
\hline & $\exp$ & 0.442 & 0.363 & 0.144 & 0.426 & 0.372 & 0.149 \\
\hline \multirow[t]{2}{*}{ Phenylalanine $(m / z$ 336) } & $\mathrm{cal}$ & 0.266 & 0.381 & 0.232 & 0.238 & 0.374 & 0.248 \\
\hline & $\exp$ & 0.266 & 0.381 & 0.232 & 0.239 & 0.371 & 0.248 \\
\hline \multirow[t]{2}{*}{ Tyrosine $(m / z 466)$} & $\mathrm{cal}$ & 0.229 & 0.355 & 0.248 & 0.205 & 0.346 & 0.256 \\
\hline & $\exp$ & 0.228 & 0.354 & 0.247 & 0.208 & 0.343 & 0.257 \\
\hline
\end{tabular}

and L-cysteine biosynthesis, and sulfate assimilation. Its deletion causes various secondary changes in the expression of genes without any known McbR binding site, suggesting a global regulatory function in C. glutamicum (Rey et al., 2003, 2005). Since the deletion of the transcriptional repressor McbR in C. glutamicum leads to strongly induced expression of L-methionine pathway genes, it is regarded as one of the key targets for a biotechnological L-methionine production process. The deletion of McbR, however, does not lead to any overproduction of L-methionine, but causes a significantly reduced growth rate and the intracellular accumulation of homolanthionine, a so far unknown metabolite in $C$. glutamicum (Krömer et al., 2006a). In this regard we have investigated in detail the metabolic effects of McbR deletion in C. glutamicum.

\section{Oxidative stress response}

The deletion of McbR causes an induction of stress proteins in C. glutamicum. At the level of the proteome (Table 4) and transcriptome (Rey et al., 2005), a number of proteins related to oxidative stress, such as catalase, are strongly increased. The major reason for oxidative stress is the presence of reactive oxygen species such as superoxides, peroxides and hydroxyl radicals, which are generated in response to deletion of McbR. A likely candidate for such a reaction is sulfite reductase, strongly induced on the level of gene expression (Rey et al., 2005) and shown elsewhere to be the major source of reactive oxygen species in Escherichia coli (Messner \& Imlay, 1999). The severe consequences of oxidative stress comprise a $50 \%$ reduction of the specific growth rate and a $30 \%$ reduction of the specific glucose uptake rate. Most striking was the drastically reduced $\mathrm{NADPH}: \mathrm{NADP}^{+}$ratio in the deletion strain, which was far below the value for the wild-type. Since NADPH is consumed by known antioxidant systems (Nogae \& Johnston, 1990; Pollak et al., 2007), the equilibrium of NADPH:NADP is a key indicator of oxidative stress (Ralser et al., 2007). Similar conclusions also hold for the $\mathrm{NADH}: \mathrm{NAD}^{+}$ratio, which was drastically disturbed in the deletion strain, probably due to an increased demand for NADH to detoxify oxidative stress, involving e.g. NADH-dependent flavin reductase (Table 4).

\section{Metabolic flux rerouting}

A central feature of the carbon flux distribution of the deletion strain is the elevated formation of NADPH. With regard to the changes in the proteome, this response of the cell at the metabolic level, i.e. fluxes and metabolites, is 
Table 3. Intracellular concentrations of intermediates of the Lmethionine and supporting pathways in wild-type C. glutamicum ATCC 13032 (WT) and C. glutamicum ATCC 13032 $\Delta m c b R$ during exponential growth on minimal glucose medium

The data shown are mean values from eight cell extracts taken at four different time points from two parallel cultures for each strain. Corresponding SD values are given. The limit of detection was $0.1 \mu \mathrm{mol}\left(\mathrm{g} \mathrm{CDM}^{-1}\right.$.

\begin{tabular}{|lcc|}
\hline Metabolite & $\begin{array}{c}\text { WT }[\boldsymbol{\mu m o l} \\
\left.(\mathbf{g} \text { CDM })^{-1}\right]\end{array}$ & $\begin{array}{c}\Delta m c b R[\boldsymbol{m o l} \\
\left.(\mathbf{g ~ C D M})^{-1}\right]\end{array}$ \\
\hline L-Arginine & $0.2 \pm 0.4$ & $2.3 \pm 0.6$ \\
Cystathionine & $0.2 \pm 0.0$ & $0.6 \pm 0.1$ \\
L-Cysteine & $0.4 \pm 0.1$ & $3.0 \pm 0.2$ \\
Glycine & $3.6 \pm 0.5$ & $1.6 \pm 0.1$ \\
L-Homocysteine & $0.1 \pm 0.0$ & $3.4 \pm 0.8$ \\
Homolanthionine & $0.8 \pm 1.5$ & $209.8 \pm 6.5$ \\
L-Homoserine & $4.6 \pm 1.2$ & $1.3 \pm 0.1$ \\
L-Isoleucine & $0.2 \pm 0.4$ & $0.5 \pm 0.2$ \\
L-Leucine & $0.3 \pm 0.6$ & $3.5 \pm 1.4$ \\
L-Methionine & $<0.1$ & $0.4 \pm 0.0$ \\
O-Acetyl-L-homoserine & $0.9 \pm 0.2$ & $0.5 \pm 0.1$ \\
2-Oxobutanoate & $<0.1$ & $0.7 \pm 0.2$ \\
L-Proline & $31.8 \pm 8.9$ & $17.4 \pm 2.7$ \\
S-Adenosyl methionine & $0.6 \pm 0.2$ & $1.0 \pm 0.1$ \\
L-Serine & $4.5 \pm 0.9$ & $1.4 \pm 0.6$ \\
L-Threonine & $2.7 \pm 0.7$ & $1.6 \pm 0.3$ \\
Trehalose & $9.0 \pm 3.0$ & $61.8 \pm 10.9$ \\
L-Valine & $7.5 \pm 0.6$ & $3.6 \pm 0.2$ \\
& & \\
\hline
\end{tabular}

mainly a response to the oxidative stress conditions, because NADPH provides the redox power for antioxidant systems (Nogae \& Johnston, 1990; Pollak et al., 2007). An enhanced supply of NADPH is found under conditions of oxidative stress in various prokaryotic and eukaryotic cells (Boada et al., 2000; Igoillo-Esteve et al., 2007; Ralser et al., 2007; Williams \& Ford, 2004). Clearly, the flux rearrangement in the central metabolism leads to greater NADPH formation, but is not sufficient for recovery from the oxidative stress conditions, as indicated by the perturbed redox state and the reduced metabolic activity. Whereas generally the PPP flux is assumed to be the most important for generation of NAPDH under oxidative stress conditions (Ralser et al., 2007), C. glutamicum $\Delta m c b R$ did not utilize this pathway to increase NADPH production, but rather employed $\mathrm{NADP}^{+}$-dependent isocitrate dehydrogenase in the TCA cycle. Obviously, flux rerouting under conditions of oxidative stress can vary depending on the cellular background and physiological conditions. The flux response might thereby depend on the cofactor specificity of the available set of enzymes. Isocitrate dehydrogenase is $\mathrm{NADP}^{+}$-dependent in C. glutamicum, whereas other species have $\mathrm{NAD}^{+}$-dependent enzymes or even both types.

\section{NADPH metabolism}

In contrast to the wild-type, in which NADPH supply matches the anabolic demand, C. glutamicum $\Delta m c b R$ showed an apparent surplus of this cofactor. This apparent excess has also been observed in previous flux studies with C. glutamicum and indicated so far unassigned fluxes of NADPH consumption, which are not linked to product or cell material formation (Wittmann \& Becker, 2007). Oxidative stress induces NADPH-dependent detoxifying reactions, as shown for E. coli (Brumaghim et al., 2003; Iuchi \& Weiner, 1996) and Staphylococcus aureus (Streker et al., 2005). Also, C. glutamicum $\triangle m c b R$, as evident from the induction of, for example, NADPH-dependent FMN reductase (Table 4), activates such reactions, suggesting that the protection from oxidative stress is linked to $\mathrm{NADPH}$ consumption. Additionally, the synthesis of homolanthionine, which accounts for about $15 \%$ of the total anabolic NADPH requirement in the deletion strain, poses a high extra demand on the cellular metabolism. Beyond the present study, oxidative stress could be a reason for the so far unassigned NADPH consumption fluxes in earlier studies with C. glutamicum, since this phenomenon is often observed in industrial fermentation processes with aerobic micro-organisms (Bai et al., 2003). Since oxidative stress and the formation of industrially relevant products such as L-lysine, L-threonine and Lmethionine compete for NADPH, such stresses might even limit production under certain conditions.

\section{Energy metabolism}

Large spherical granules with a high phosphorus content were exclusively observed in the $\Delta m c b R$ strain. From their shape, their low number per cell and the chemical composition, we conclude that these are volutin granules, recently identified in C. glutamicum as inorganic, energyrich polyphosphates (Pallerla et al., 2005). In the present work, the measured carbon fluxes allow a quantitative insight into the energy metabolism of C. glutamicum. The following calculation shows that, in contrast to the wildtype, the mutant exhibits a strong excess of ATP. For the wild-type, the relative flux of catabolic ATP supply ( $870 \%)$ and anabolic demand $(845 \%)$ were similar, indicating a balanced energy metabolism. In the mutant, however, a strong apparent ATP excess is obtained from calculation of catabolic ATP supply flux $(1150 \%)$ and anabolic ATP demand $(580 \%)$. Although these calculations provide only a rough estimate and cannot account, for example, for the maintenance ATP requirement or for NADH, consumed in the anti-oxidative system and not directed towards the respiratory chain, we conclude that in C. glutamicum $\triangle m c b R$, a dominating fraction of the generated ATP is not utilized for growth. It appears very likely that this ATP excess is partly directed towards the storage of energy-rich polyphosphate and triggers the formation of the volutin granules. The apparent ATP excess probably also causes the observed intensified cycling of carbon between $\mathrm{C}_{4}$ meta- 

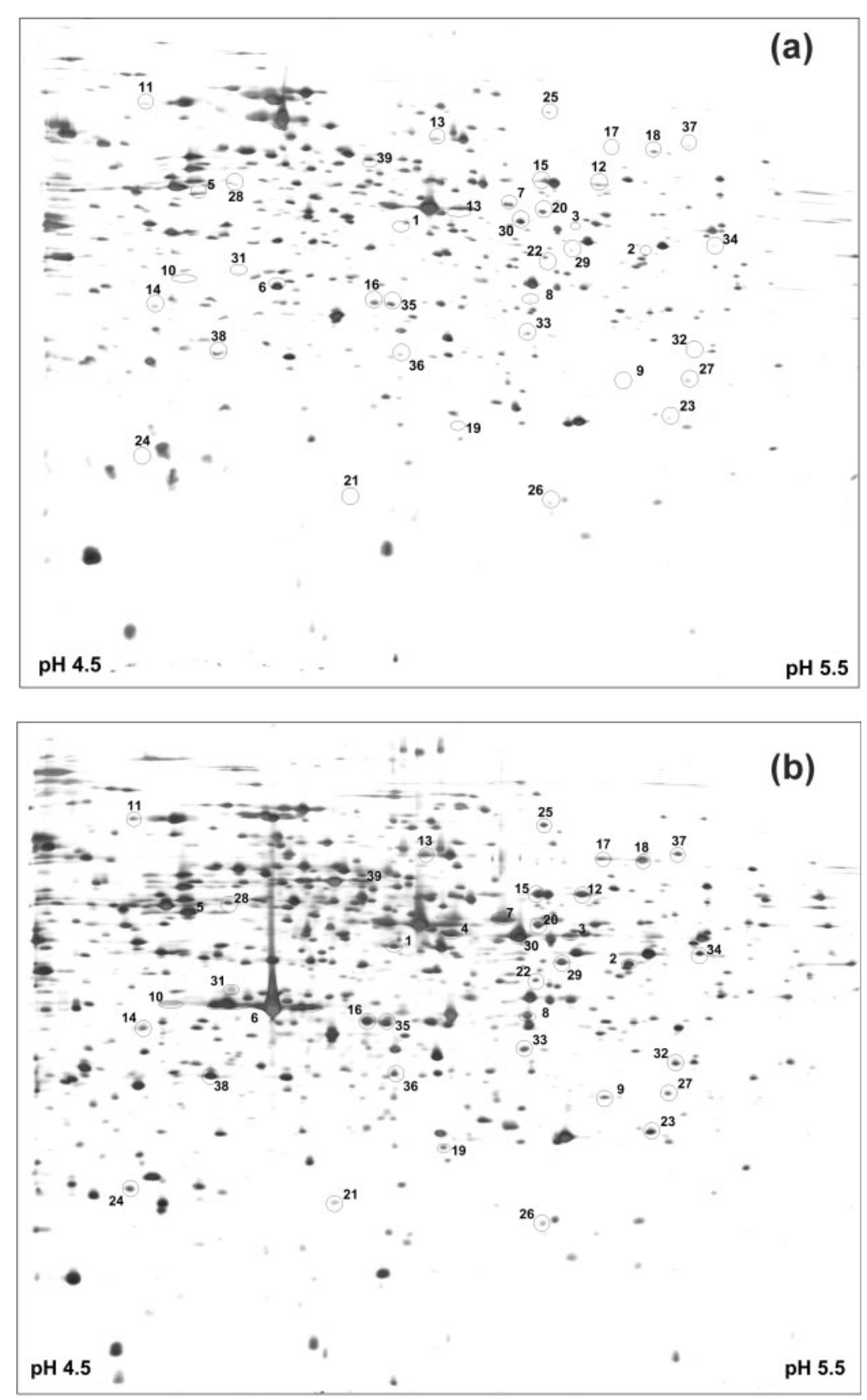

Fig. 5. 2D SDS-PAGE of cytosolic proteins from C. glutamicum ATCC 13032 (a) and C. glutamicum ATCC $13032 \Delta m c b R$ (b) with IEF in the $\mathrm{pH}$ range 4.5-5.5. Proteins corresponding to spots with a more than twofold difference in size were regarded as differentially expressed and subsequently identified by MS analysis. Their numbering refers to the annotation provided in Tables 4 and 5 . bolites of the TCA cycle and $\mathrm{C}_{3}$ metabolites of glycolysis, since this cycle allows the waste of excess ATP.

\section{L-Methionine biosynthesis and supporting pathways}

The present study revealed that $m c b R$ deletion leads to increased levels of the L-methionine biosynthetic proteins MetB, MetX, MetY and MetK, as well as changes in the intracellular level of pathway intermediates. These data complement the previous picture, which already demonstrated a strongly increased expression and activity of genes and proteins of the L-methionine pathway (Rey et al., 2003, 2005) and a perturbation of corresponding metabolite levels (Krömer et al., 2006a). In addition to the previously described strong accumulation of L-homocysteine and homolanthionine, the present study revealed a significantly increased level of intracellular L-methionine and $S$ adenosyl methionine. Although the relative increase was large, the absolute levels remained very low, and no extracellular L-methionine could be detected. The intermediate 2-oxobutanoate, as a product of homolanthionine degradation by AecD (cystathionine- $\beta$-lyase) and as a precursor of L-isoleucine, is the so far missing link between 
Table 4. Proteins differentially expressed in wild-type C. glutamicum ATCC 13032 and C. glutamicum ATCC $13032 \Delta m c b R$

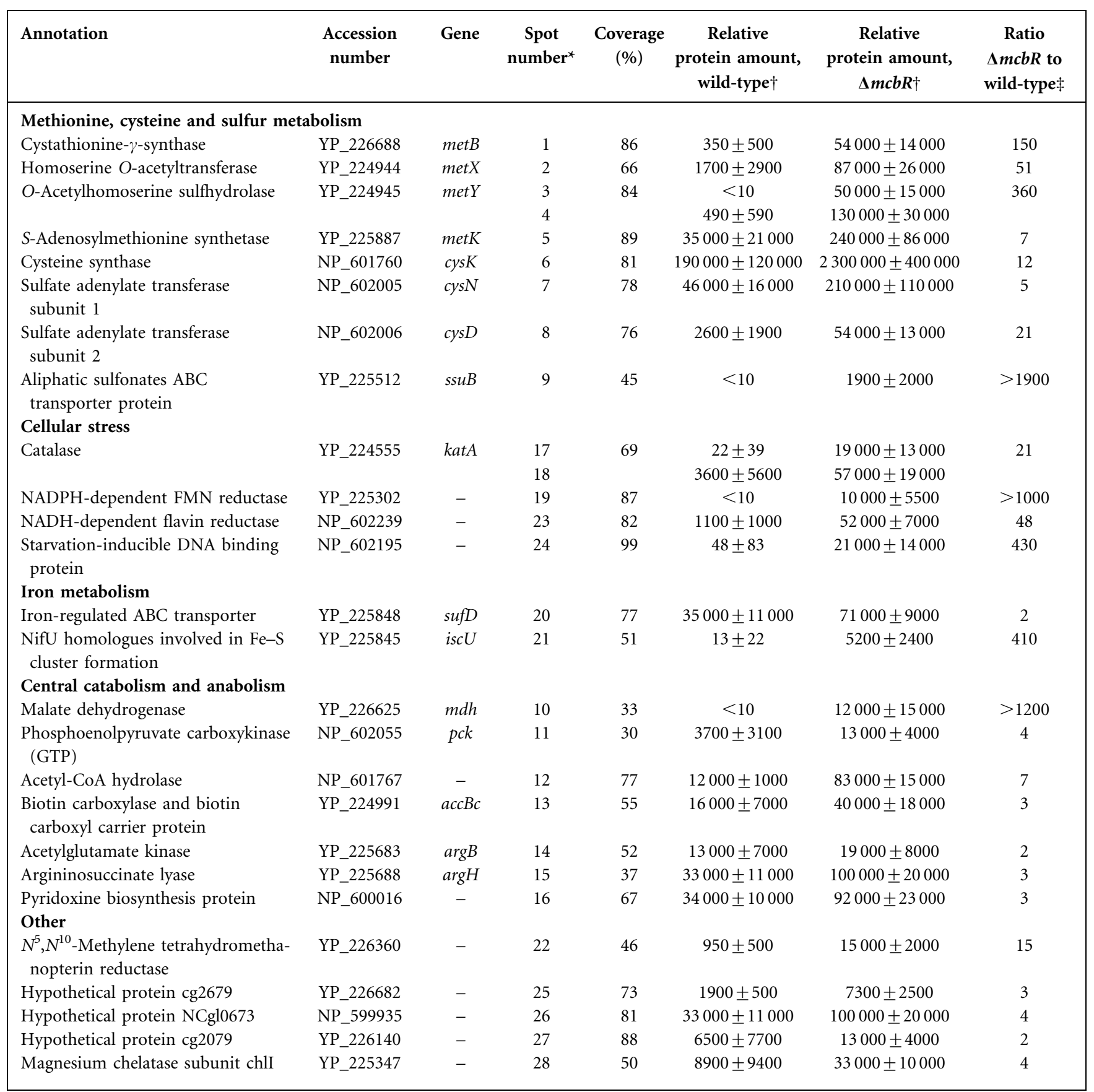

${ }^{\star}$ The spot number corresponds to the $2 \mathrm{D}$ gels shown in Fig. $5(\mathrm{a}, \mathrm{b})$.

$\dagger$ The relative protein amount represents the mean value of four independent gels for each strain obtained from two samples each from two parallel cultures. Identical protein amounts were used in the IEF.

\$The expression ratio of wild-type to the mutant.

these two pathways. Here, we were able to show that the cleavage of homolanthionine results in an increased level of 2-oxobutanoate, which itself most likely triggers the enhanced formation of L-isoleucine (Table 3). It is known that 2-oxobutanoate is an inducer for $i l v B$, a gene of $\mathrm{L}-$ isoleucine biosynthesis (Willis et al., 2005).

\section{Limitation of L-methionine overproduction}

From a biotechnological view-point, the identification of the mechanisms responsible for the missing L-methionine overproduction is crucial. A central reason seems to be the limitation of NADPH, as indicated by the low 
Table 5. Proteins differentially expressed in C. glutamicum wild-type and McbR deletion mutant

The spots shown here contained more than one single protein, allowing the identification only of candidates affected by McbR deletion.

\begin{tabular}{|c|c|c|c|c|c|c|}
\hline Annotation & $\begin{array}{c}\text { Accession } \\
\text { number }\end{array}$ & Gene & $\begin{array}{c}\text { Spot } \\
\text { number }^{*}\end{array}$ & $\begin{array}{c}\text { Relative } \\
\text { protein amount, } \\
\text { wild-type } \dagger\end{array}$ & $\begin{array}{c}\text { Relative } \\
\text { protein amount, } \\
\Delta m c b R \dagger\end{array}$ & $\begin{array}{c}\text { Ratio } \\
\Delta m c b R \text { to } \\
\text { wild-type } \neq\end{array}$ \\
\hline NADH oxidoreductase & NP_602238 & - & 29 & $1100 \pm 400$ & $62000 \pm 10000$ & 58 \\
\hline Homoserine $O$-acetyltransferase & YP_224944 & met $X$ & & & & \\
\hline O-Acetyl-L-homoserine sulfhydrolase & YP_224945 & met $Y$ & 30 & $62000 \pm 17000$ & $360000 \pm 60000$ & 6 \\
\hline Selenocysteine lyase & NP_600776 & - & & & & \\
\hline $\mathrm{NADPH}$ : quinone reductase & YP_225856 & qor & 31 & $1900 \pm 3300$ & $18000 \pm 10000$ & 9 \\
\hline Cysteine synthase & NP_601760 & cys $K^{*}$ & & & & \\
\hline Phosphoadenosine phosphosulfate reductase & YP_227054 & $c y s H$ & 32 & $360 \pm 490$ & $30000 \pm 3000$ & 84 \\
\hline Ribosome-associated protein Y & YP_225048 & - & & & & \\
\hline Glutamine amidotransferase & NP_600757 & - & 33 & $10000 \pm 3000$ & $31000 \pm 5000$ & 3 \\
\hline $\begin{array}{l}\text { Polyprenol-phosphate-mannose synthase } \\
\text { domain } 1\end{array}$ & YP_225764 & ppmC & & & & \\
\hline Transcriptional regulator & NP_599374 & - & 34 & $620 \pm 580$ & $39000 \pm 5000$ & 63 \\
\hline Glyceraldehyde-3-phosphate dehydrogenase & NP_600802 & - & & & & \\
\hline Pyridoxine biosynthesis protein & NP_600016 & - & 35 & $30000 \pm 5000$ & $79000 \pm 23000$ & 3 \\
\hline Dehydrogenase & NP_601335 & - & & & & \\
\hline Sulfate adenylate transferase subunit 2 & NP_602006 & $c y s D$ & & & & \\
\hline Short-chain dehydrogenase & YP_226444 & - & 36 & $9400 \pm 5500$ & $22000 \pm 13000$ & 2 \\
\hline Biotin-protein ligase & YP_225000 & birA & & & & \\
\hline Dihydroxy-acid dehydratase & YP_225557 & $i l v D$ & 37 & $450 \pm 770$ & $21000 \pm 9000$ & 47 \\
\hline Catalase & YP_224555 & katA & & & & \\
\hline $\begin{array}{l}\text { Putative electron transfer flavoprotein } \\
\text { beta-subunit }\end{array}$ & YP_225519 & fixA & 38 & $48000 \pm 5000$ & $140000 \pm 40000$ & 3 \\
\hline Starvation-inducible DNA binding protein & YP_227250 & $d p s$ & & & & \\
\hline Glutamine synthase & NP_601417 & - & 39 & $<10$ & $120000 \pm 20000$ & $>12000$ \\
\hline NADPH : ferredoxin oxidoreductase & YP_227057 & fFpr2 & & & & \\
\hline
\end{tabular}

${ }^{\star}$ The spot number corresponds to the $2 \mathrm{D}$ gels shown in Fig. $5(\mathrm{a}, \mathrm{b})$.

$\dagger$ The relative protein amount represents the mean value of four independent gels for each strain obtained from two samples each from two parallel cultures. Identical protein amounts were used in the IEF.

$¥$ The expression ratio of wild-type to the mutant.

NADPH:NADP ratio, especially with respect to the high demand for this cofactor during L-methionine biosynthesis. The strong homolanthionine accumulation withdraws substantial amounts of carbon from the Lmethionine pathway, and this could also limit the production of L-methionine. This, however, is not the major reason, because deletion of MetB in C. glutamicum $\Delta m c b R$, completely preventing homolanthionine formation, does not result in an increased L-methionine pool or L-methionine secretion (data not shown). Another possible limitation, involving $\mathrm{C}_{1}$ supply from methyltetrahydrofolate (THF) during the terminal step of Lmethionine biosynthesis, is suggested from the limited availability of L-serine, which functions as the donor of the $\mathrm{C}_{1}$ carbon during regeneration of methyl-THF. The low L-serine availability is probably due to the activation of L-cysteine biosynthesis (Rey et al., 2003, 2005) competing for L-serine as the L-cysteine precursor. The limited formation of $\mathrm{C}_{1}$ carbon also explains why the intracellular and extracellular glycine levels were significantly reduced in C. glutamicum $\Delta m c b R$ (Table 1). The fact that feeding C. glutamicum $\Delta m c b R$ with $10 \mathrm{mM}$ L-serine as $\mathrm{C}_{1}$ donor in the culture broth leads to an increased intracellular L-methionine concentration suggests that the low availability of methyl-THF is indeed involved, but that it is not the only factor that limits L-methionine overproduction. A limitation at the level of export from the cell can be excluded, since this would lead to much higher intracellular concentrations, as observed for Llysine production (Krömer et al., 2004).

\section{ACKNOWLEDGEMENTS}

We thank Herbert Platsch (BASF SE, Ludwigshafen, Germany) for proteome analysis, Pedro Mestres (Department of Anatomy, Saarland University, Homburg, Germany) for electron microscopy and assistance during interpretation, and Klaus Heckmann (BASF SE) for EDX analysis. This work was financially supported by BASF SE. 


\section{REFERENCES}

Bai, Z., Harvey, L. M. \& McNeil, B. (2003). Oxidative stress in submerged cultures of fungi. Crit Rev Biotechnol 23, 267-302.

Baker, D. H. \& Boebel, K. P. (1980). Utilization of the D- and Lisomers of methionine and methionine hydroxy analogue as determined by chick bioassay. J Nutr 110, 959-964.

Becker, J., Klopprogge, C., Herold, A., Zelder, O., Bolten, C. J. \& Wittmann, C. (2007). Metabolic flux engineering of L-lysine production in Corynebacterium glutamicum - over expression and modification of G6P dehydrogenase. J Biotechnol 132, 99-109.

Bernofsky, C. \& Swan, M. (1973). An improved cycling assay for nicotinamide adenine dinucleotide. Anal Biochem 53, 452-458.

Blum, H., Beier, H. \& Gross, H. J. (1987). Improved silver staining of plant proteins, RNA and DNA in polyacrylamide gels. Electrophoresis 8, 93-99.

Boada, J., Roig, T., Perez, X., Gamez, A., Bartrons, R., Cascante, M. \& Bermudez, J. (2000). Cells overexpressing fructose-2,6-bisphosphatase showed enhanced pentose phosphate pathway flux and resistance to oxidative stress. FEBS Lett 480, 261-264.

Bolten, C. J., Kiefer, P., Letisse, F., Portais, J. C. \& Wittmann, C. (2007). Sampling for metabolome analysis of microorganisms. Anal Chem 79, 3843-3849.

Brumaghim, J. L., Li, Y., Henle, E. \& Linn, S. (2003). Effects of hydrogen peroxide upon nicotinamide nucleotide metabolism in Escherichia coli: changes in enzyme levels and nicotinamide nucleotide pools and studies of the oxidation of $\mathrm{NAD}(\mathrm{P}) \mathrm{H}$ by $\mathrm{Fe}(\mathrm{III})$. J Biol Chem 278, 42495-42504.

de Hollander, J. A. (1994). Potential metabolic limitations in lysine production by Corynebacterium glutamicum as revealed by metabolic network analysis. Appl Microbiol Biotechnol 42, 508-515.

D'Mello, J. P. F. \& Lewis, D. (1978). Effect of Nutrient Deficiencies in Animals: Amino Acids, pp. 441-490. Edited by M. Rechgigl. CRC Handbook Series in Nutrition and Food. Boca Raton, FL, CRC Press.

Eggeling, L. \& Sahm, H. (1999). L-Glutamate and L-lysine: traditional products with impetuous developments. Appl Microbiol Biotechnol 52, $146-153$.

Friedman, M. (1999). Chemistry, nutrition, and microbiology of Damino acids. J Agric Food Chem 47, 3457-3479.

Haitani, Y., Awano, N., Yamazaki, M., Wada, M., Nakamori, S. \& Takagi, H. (2006). Functional analysis of L-serine $O$-acetyltransferase from Corynebacterium glutamicum. FEMS Microbiol Lett 255, 156-163.

Hermann, T., Pfefferle, W., Baumann, C., Busker, E., Schaffer, S., Bott, M., Sahm, H., Dusch, N., Kalinowski, J. \& other authors (2001). Proteome analysis of Corynebacterium glutamicum. Electrophoresis 22, 1712-1723.

Hwang, B. J., Kim, Y., Kim, H. B., Hwang, H. J., Kim, J. H. \& Lee, H. S. (1999). Analysis of Corynebacterium glutamicum methionine biosynthetic pathway: isolation and analysis of metB encoding cystathionine $\gamma$-synthase. Mol Cells 9, 300-308.

Hwang, B. J., Yeom, H. J., Kim, Y. \& Lee, H. S. (2002). Corynebacterium glutamicum utilizes both transsulfuration and direct sulfhydrylation pathways for methionine biosynthesis. J Bacteriol 184, 1277-1286.

Igoillo-Esteve, M., Maugeri, D., Stern, A. L., Beluardi, P. \& Cazzulo, J. J. (2007). The pentose phosphate pathway in Trypanosoma cruzi: a potential target for the chemotherapy of Chagas disease. An Acad Bras Cienc 79, 649-663.

luchi, S. \& Weiner, L. (1996). Cellular and molecular physiology of Escherichia coli in the adaptation to aerobic environments. J Biochem 120, 1055-1063.
Kiefer, P., Heinzle, E., Zelder, O. \& Wittmann, C. (2004). Comparative metabolic flux analysis of lysine-producing Corynebacterium glutamicum cultured on glucose or fructose. Appl Environ Microbiol 70, 229239.

Kim, J. W., Kim, H. J., Kim, Y., Lee, M. S. \& Lee, H. S. (2001). Properties of the Corynebacterium glutamicum metC gene encoding cystathionine $\beta$-lyase. Mol Cells 11, 220-225.

Krömer, J. O., Sorgenfrei, O., Klopprogge, K., Heinzle, E. \& Wittmann, C. (2004). In-depth profiling of lysine-producing Corynebacterium glutamicum by combined analysis of the transcriptome, metabolome, and fluxome. J Bacteriol 186, 1769-1784.

Krömer, J. O., Fritz, M., Heinzle, E. \& Wittmann, C. (2005). In vivo quantification of intracellular amino acids and intermediates of the methionine pathway in Corynebacterium glutamicum. Anal Biochem 340, 171-173.

Krömer, J. O., Heinzle, E., Schröder, H. \& Wittmann, C. (2006a). Accumulation of homolanthionine and activation of a novel pathway for isoleucine biosynthesis in Corynebacterium glutamicum McbR deletion strains. J Bacteriol 188, 609-618.

Krömer, J. O., Heinzle, E. \& Wittmann, C. (2006b). Quantification of $S$-adenosyl methionine in microbial cell extracts. Biotechnol Lett 28, 69-71.

Lee, H. S. \& Hwang, B. J. (2003). Methionine biosynthesis and its regulation in Corynebacterium glutamicum: parallel pathways of transsulfuration and direct sulfhydrylation. Appl Microbiol Biotechnol 62, 459-467.

Messner, K. R. \& Imlay, J. A. (1999). The identification of primary sites of superoxide and hydrogen peroxide formation in the aerobic respiratory chain and sulfite reductase complex of Escherichia coli. J Biol Chem 274, 10119-10128.

Moritz, B., Striegel, K., De Graaf, A. A. \& Sahm, H. (2000). Kinetic properties of the glucose-6-phosphate and 6-phosphogluconate dehydrogenases from Corynebacterium glutamicum and their application for predicting pentose phosphate pathway flux in vivo. Eur $\mathrm{J}$ Biochem 267, 3442-3452.

Nogae, I. \& Johnston, M. (1990). Isolation and characterization of the ZWF1 gene of Saccharomyces cerevisiae, encoding glucose-6-phosphate dehydrogenase. Gene 96, 161-169.

Pallerla, S. R., Knebel, S., Polen, T., Klauth, P., Hollender, J., Wendisch, V. F. \& Schoberth, S. M. (2005). Formation of volutin granules in Corynebacterium glutamicum. FEMS Microbiol Lett 243, 133-140.

Park, S. D., Lee, J. Y., Kim, Y., Kim, J. H. \& Lee, H. S. (1998). Isolation and analysis of metA, a methionine biosynthetic gene encoding homoserine acetyltransferase in Corynebacterium glutamicum. Mol Cells 8, 286-294.

Perkins, D. N., Pappin, D. J., Creasy, D. M. \& Cottrell, J. S. (1999). Probability-based protein identification by searching sequence databases using mass spectrometry data. Electrophoresis 20, 35513567.

Pollak, N., Dolle, C. \& Ziegler, M. (2007). The power to reduce: pyridine nucleotides - small molecules with a multitude of functions. Biochem J 402, 205-218.

Popov, N., Schmitt, M., Schulzeck, S. \& Matthies, H. (1975). Reliable micromethod for determination of the protein content in tissue homogenates. Acta Biol Med Ger 34, 1441-1446.

Ralser, M., Wamelink, M. M., Kowald, A., Gerisch, B., Heeren, G., Struys, E. A., Klipp, E., Jakobs, C., Breitenbach, M. \& other authors (2007). Dynamic rerouting of the carbohydrate flux is key to counteracting oxidative stress. J Biol 6, 10.

Rey, D. A., Pühler, A. \& Kalinowski, J. (2003). The putative transcriptional repressor McbR, member of the TetR-family, is 
involved in the regulation of the metabolic network directing the synthesis of sulfur containing amino acids in Corynebacterium glutamicum. J Biotechnol 103, 51-65.

Rey, D. A., Nentwich, S. S., Koch, D. J., Rückert, C., Pühler, A., Tauch, A. \& Kalinowski, J. (2005). The McbR repressor modulated by the effector substance $S$-adenosyl homocysteine controls directly the transcription of a regulon involved in sulphur metabolism of Corynebacterium glutamicum ATCC 13032. Mol Microbiol 56, 871-887.

Rückert, C., Pühler, A. \& Kalinowski, J. (2003). Genome-wide analysis of the L-methionine biosynthetic pathway in Corynebacterium glutamicum by targeted gene deletion and homologous complementation. J Biotechnol 104, 213-228.

Rückert, C., Koch, D. J., Rey, D. A., Albersmeier, A., Mormann, S., Pühler, A. \& Kalinowski, J. (2005). Functional genomics and expression analysis of the Corynebacterium glutamicum fpr2cysIXHDNYZ gene cluster involved in assimilatory sulphate reduction. BMC Genomics 6, 121.

Streker, K., Freiberg, C., Labischinski, H., Hacker, J. \& Ohlsen, K. (2005). Staphylococcus aureus NfrA (SA0367) is a flavin mononucleotide-dependent NADPH oxidase involved in oxidative stress response. J Bacteriol 187, 2249-2256.

Varela, C., Agosin, E., Baez, M., Klapa, M. \& Stephanopoulos, G. (2003). Metabolic flux redistribution in Corynebacterium glutamicum in response to osmotic stress. Appl Microbiol Biotechnol 60, 547-555.

Varela, C. A., Baez, M. E. \& Agosin, E. (2004). Osmotic stress response: quantification of cell maintenance and metabolic fluxes in a lysine-overproducing strain of Corynebacterium glutamicum. Appl Environ Microbiol 70, 4222-4229.

Williams, A. C. \& Ford, W. C. (2004). Functional significance of the pentose phosphate pathway and glutathione reductase in the antioxidant defenses of human sperm. Biol Reprod 71, 1309-1316.

Willis, L. B., Lessard, P. A. \& Sinskey, A. J. (2005). Synthesis of Lthreonine and branched-chain amino acids. In Handbook of
Corynebacterium glutamicum, pp. 511-531. Edited by L. Eggeling \& M. Bott. Boca Raton, FL: CRC Press, Taylor and Francis.

Wittmann, C. \& Becker, J. (2007). The L-lysine story: from metabolic pathways to industrial production. In Amino Acid Biosynthesis Pathways, Regulation and Metabolic Engineering (Microbiology Monographs volume 5), pp. 39-70. Edited by V. F. Wendisch. Berlin/Heidelberg: Springer.

Wittmann, C. \& de Graaf, A. (2005). Metabolic flux analysis in Corynebacterium glutamicum. In Handbook of Corynebacterium glutamicum, pp. 277-304. Edited by L. Eggeling \& M. Bott. Boca Raton, FL: CRC Press.

Wittmann, C. \& Heinzle, E. (2001). Modeling and experimental design for metabolic flux analysis of lysine-producing corynebacteria by mass spectrometry. Metab Eng 3, 173-191.

Wittmann, C. \& Heinzle, E. (2002). Genealogy profiling through strain improvement by using metabolic network analysis: metabolic flux genealogy of several generations of lysine-producing corynebacteria. Appl Environ Microbiol 68, 5843-5859.

Wittmann, C., Kiefer, P. \& Zelder, O. (2004a). Metabolic fluxes in Corynebacterium glutamicum during lysine production with sucrose as carbon source. Appl Environ Microbiol 70, 7277-7287.

Wittmann, C., Kim, H. M. \& Heinzle, E. (2004b). Metabolic network analysis of lysine producing Corynebacterium glutamicum at a miniaturized scale. Biotechnol Bioeng 87, 1-6.

Wittmann, C., Krömer, J. O., Kiefer, P., Binz, T. \& Heinzle, E. (2004c). Impact of the cold shock phenomenon on quantification of intracellular metabolites in bacteria. Anal Biochem 327, 135-139.

Yang, T. H., Wittmann, C. \& Heinzle, E. (2006). Respirometric ${ }^{13} \mathrm{C}$-flux analysis. Part II: in vivo flux estimation of lysine-producing Corynebacterium glutamicum. Metab Eng 8, 432-446.

Edited by: M. Hecker 